Mila Beljanski*

Pedagoški fakultet u Somboru

Univerzitet u Novom Sadu

\section{Borka Malčić}

Filozofski fakultet

Univerzitet u Novom Sadu
UDK: 364-43:[371.12:36-051]

DOI: $10.19090 /$ gff.2020.2.43-56

Stručni naučni rad

\title{
IZAZOVI VODITELJA SLUČAJA U CENTRIMA ZA SOCIJALNI RAD: IMPLIKACIJE ZA OBRAZOVNI SISTEM
}

Polazeći od činjenice da prosvetni radnici u školama često nisu upoznati sa načinom rada centra za socijalni rad, u radu su apostrofirana pitanja putem kojih se operacionalizuje fenomen vođenja slučaja u centrima za socijalni rad i analizirana je uloga voditelja slučaja u cilju bolje saradnje socijalnih službi i obrazovnih ustanova. Cilj ovog rada bio je upoznavanje i integracija teorije i prakse vođenja slučaja iz perspektive voditelja slučaja sa obrazovnim ustanovama, čije su usluge povezane i koje su u direktnoj vezi i saradnji sa radom centara i socijalnih službi. Da bi saradnja bila uspešna obrazovni sistem mora da poznaje način rada, domete i mogućnosti stručnjaka zaposlenih u organima starateljstva. Jedino na taj način pomoć stručnjaka, u ovom slučaju voditelja slučaja, može biti potpuna kao i interakcija ova dva sistema. Potvrđena je potreba za uspostavljanjem i negovanjem dijaloga i saradničkih odnosa kroz interdisciplinarni pristup, sinergijom delovanja različitih sektora.

Ključne reči: centar za socijalni rad, vođenje slučaja, obrazovni sistem, voditelj slučaja.

\section{UVOD}

Nauka socijalnog rada započela je svoj razvojni put sistematizovanjem saznanja do kojih su dolazili praktičari s kraja XIX i početkom XX veka. U početku dobrovoljci (volonteri) a kasnije profesionalci (socijalni radnici), suočavali su se sa aktuelnim društvenim problemima tog doba (Walter, 2001). Od osnivanja centara za socijalni rad u Srbiji prošlo je nešto više od šezdeset godina. U tom periodu centri su prošli nekoliko formi unutrašnje organizacije čiji je cilj bio prilagođavanje rada centra uslovima i sadržajima rada. U početku osnovani i organizovani kao

*mila.beljanski@uns.ac.rs 
stručne službe opštinskih organa nadležnih za poslove socijalne zaštite, centri nisu imali preciznije utvrđenu unutrašnju organizaciju, već se podela rada vršila prostom distribucijom predmeta. Novu fazu unutrašnje organizacije centara karakteriše podela posla na stručne službe, u nekim centrima prema kategorijama korisnika, oblicima zaštite, a u nekima se praktikovao kombinovani rad koji se sastojao od rada po kategorijama i rada zasnovanog na teritorijalnom principu. Nakon ovakve organizacije rada uvedeni su stabilni, stalni timovi u kojima je zajednički radilo više stručnih saradnika raznih profila (npr. tim za maloletničku delinkvenciju koji su činili socijalni radnik, psiholog i pedagog ili specijalni pedagog, po potrebi pravnik). Ovakav timski rad proistekao je iz složenosti i kompleksnosti socijalnozaštitnih potreba pojedinaca, porodica i grupa ljudi kao i socijalnih potreba i problema koji su se tada javili (nasilje, siromaštvo, sukob sa zakonom, diskriminacija). Veliki problem u ovakvoj organizaciji rada nastao je u raspodeli i obimu posla kao i kolektivnoj odgovornosti koja se javila oko takve organizacije rada. U prevazilaženju navedenih problema, kao i fragmentacije usluga, pozitivna promena u centrima za socijalni rad javlja se sa pojavom pristupa vođenja slučaja.

U Srbiji je vođenje slučaja kao metod rada u centrima za socijalni rad počeo da se razvija 2002. godine, a ubrzano se uvodi u praksu od 2006. godine. Standardi za vođenje slučaja su zakonski uvedeni juna 2008. godine i centar menja svoj način rada: od tada je organizovan po službama, a ne po timovima, dok su stručni radnici od tada voditelji slučaja (Žegarac, 2015). Ovakva situacija se zadržala do danas. Redefinisanje pristupa ovog tipa u socijalnoj zaštiti podrazumeva pomeranje težišta na pitanje kako obezbediti da se sva javna ovlašćenja koja centar za socijalni rad ima i usluge koje pruža ova ustanova socijalne zaštite za sve korisnike bude podržavajuća i pristupačna. Savremeni, holistički pristup problemima i potrebama prevazilazi parcijalnost klasičnog pristupa u socijalnom radu, pokušavajući da obuhvati korisnika u celini gde pojedinac nije jedini fokus procene, jer porodica, vršnjačke grupe i faktori šire sredine važan su izvor saznanja i mogućnosti prepoznavanja problema kao i zajedničke saradnje na rešavanju problema (Žegarac, 2004). Važno je istaći da se problem ne rešava za korisnika nego sa korisnikom, u saradnji sa njim procenjuju se potrebe i koordinišu usluge zastupajući najbolji interes korisnika.

Voditelji slučaja u ustanovama socijalne zaštite se bave nekim od najsloženijih problema i alternativnim oblastima ljudskog iskustva, pa je to delatnost koja zahteva složena i razvijena znanja i veštine. U svetu prepoznavanje značaja profesije socijalnog rada postoji odavno. U Srbiji je Viša škola za socijalne radnike osnovana još 1957. godine, dok je 1970. godine u Rezoluciji o socijalnoj 
zaštiti socijalni rad prepoznat kao profesionalna delatnost (Žegarac, 2016a), a od 1972. godine Odeljenje za socijalnu politiku i socijalni rad Fakulteta političkih nauka Univerziteta u Beogradu obrazuje diplomirane socijalne radnike. $\mathrm{Na}$ Filozofskom fakultetu u Novom Sadu od školske 2017/18. godine osnovan je Odsek za socijalni rad.

Danas je centar za socijalni rad organizovan po službama: služba za zaštitu dece i mladih; služba za zaštitu odraslih i starih; služba za pravne poslove i služba za finansijsko-administrativne i tehničke poslove. U okviru svake od tih službi postoji rukovodilac službe koji obezbeđuje unutrašnju koordinaciju i organizaciju, planiranje i upravljanje obimom posla unutar službe, poštovanje standarda stručnog rada, zakonitost rada i poštovanje rokova i procedura. Takođe, svaka služba ima voditelje slučaja koji su stručni radnici za konkretan slučaj kao i supervizora čiji je zadatak poštovanje standarda stručnog rada i obezbeđivanje kvaliteta usluga. U centrima za socijalni rad postoje timovi i timski rad, ali ti timovi nisu stalni nego povremeni u zavisnosti od slučaja i potreba korisnika i porodica.

Prosvetni radnici u školama vrlo često nisu upoznati sa načinom rada centara za socijalni rad. Time nemaju jasnu sliku šta mogu od stručnih radnika centara da očekuju, kao i to koji su načini i mogućnosti saradnje ove dve vrlo važne institucije. Stoga je svrha ovog rada upoznavanje sa teorijom i praksom socijalnog rada radi uspešnije saradnje socijalnih službi i obrazovnih ustanova.

Cilj ovog rada je upoznavanje sa teorijom i praksom i vođenja slučaja iz perspektive voditelja slučaja. Predstavljeni su pristupi, faze i ciklusi vođenja slučaja u centrima za socijalni rad, zatim zadaci i uloge voditelja slučaja u radu kroz saradnju sa obrazovnim ustanovama čije su usluge povezane i koje su u direktnoj vezi sa radom centara i socijalnih službi. Na kraju su predstavljene potencijalne imlikacije za obrazovni sistem i zaključci istraživanja.

\section{VOĐENJE SLUČAJA U CENTRIMA ZA SOCIJALNI RAD}

Počeci vođenja slučaja (Whitaker, Weismiller, \& Clark, 2006) vezuju se za nastanak profesije socijalnog rada, a ono ostaje integralni deo prakse i u XXI veku. Vođenje slučaja je metod socijalnog rada u kojem se, u saradnji sa korisnikom, procenjuju potrebe, aranžiraju i koordinišu usluge, obavljaju monitoring i evaluacija i zastupa najbolji interes korisnika (NASW, 2013). Sa pravom se naglašava da kovanica 'vođenje slučaja' (case management) nije najpodobniji termin, te da može da zvuči depersonalizovano - kao da se slučaj sam vodi, odnosno da ima onih koji korisnika poistovećuju sa slučajem (Ajduković i Urbanac, 2009). 
Postoje dva pristupa prema kojima voditelji slučaja u socijalnim službama obavljaju profesionalnu delatnost: tradicionalni i antipotčinjavajući pristup (Mihajlović Babić, Despotović, \& Đaković, 2019). Tradicionalni pristup se zasniva na socijalnom radu sa pojedincem, dok se kod antipotčinjavajućeg pristupa koristi višemetodski pristup. Tradicionalni pristup definiše problem klijenta onako kako je on definisan uslugom, pri čemu su profesionalne granice i mogućnosti jasno postavljene (Strier \& Binyamin 2010). Sa druge strane, „uloga socijalnih radnika koji praktikuju antipotčinjavajući pristup je da kroz partnerstvo sa korisnikom definišu problem, uključe korisnika u proces donošenja odluka i kroz profesionalno učešće koriste različite sisteme i institucije u cilju otklanjanja uzroka siromaštva i unapređenja položaja korisnika" (Mihallović Babić, 2017: 157). Uključivanje korisnika u rešavanje problema blisko je socijalnom konstruktivizmu po kojem se znanje o nečemu razvija u svakodnevnoj interakciji ljudi i kroz njihovo pregovaranje o značenjima (Ajduković, 2008), pa tako različite društvene grupe određenom socijalnom problemu pripisuju različita značenja i uzroke.

Savremeni pristupi (od devedesetih godina XX veka) znatno veći naglasak stavljaju na saradnju, partnerstvo, kolaborativni pristup, potpuno učešće, pravo na izbor korisnika i personalizaciju usluga. Time se napušta tradicionalni paternalistički okvir koji je bio karakterističan za pristupe u socijalnom radu u kojem je profesionalac preuzimao kontrolu nad životom korisnika ,za njegovo dobro“, zanemarujući pri tom njegove sopstvene izbore, želje i preferencije, kao i mogućnost da korisnik sam donosi odluke koje su zasnovane na informacijama (Žegarac, 2016a). Pristup vođenju slučaja koji zastupamo u ovom radu podrazumeva kreativan i kolaborativan proces $\mathrm{u}$ kome se veštine procene, planiranja, konsultacije, podučavanja, modelovanja i zastupanja koriste radi unapređenja i optimizacije socijalnog funkcionisanja korisnika (Woodside \& McClam, 2003). Voditelji slučaja su profesionalni pomagači, a cilj njihovog rada je pomoć onima kojima je takva pomoć potrebna da bi upravljali sopstvenim životom, odnosno onima kojima je potrebna podrška u situacijama krize. Prema ovom načinu rada, svakom korisniku usluga u centru za socijalni rad dodeljeno je odgovorno lice, voditelj slučaja, koje je zaduženo za određeni slučaj i koje sačinjava početnu procenu i organizuje dalju usmerenu ili specijalizovanu procenu. Stoga, vođenje slučaja predstavlja sistemski pristup koji se koristi u socijalnom radu, a obuhvata procenu, organizaciju pristupa uslugama, planiranje, aktivnosti koordinacije, nadzora i evaluacije primene mera i usluga koje treba da odgovore na potrebe konkretnog korisnika (Žegarac, 2007). 
Cilj socijalnog rada je da pomaže korisnicima usluga i onima koji se o njima staraju da ostvare lični integritet i socijalnu uključenost u sopstvenom porodičnom i društvenom životu, odnosno u životu zajednice (NASW, 2013). Ovakva praksa podrazumeva refleksivnog praktičara koji stalno promišlja sopstveno delovanje iz korisničke perspektive i perspektive drugih uključenih aktera.

\section{FAZE I CIKLUS VOĐENJA SLUČAJA}

Payne (2000) ukazuje na pet glavnih faza vođenja slučaja i naglašava cikličnost procesa (prema Žegarac, 2015:21). Prva faza je procena potreba korisnika (prikupljanja podataka, prepoznavanja i ocene problema, potreba, snaga i rizika, situacije i uključenih osoba), u drugoj fazi voditelj slučaja sa korisnikom planira i formira paket usluga (pružanje usluga prilagođeno je potrebama korisnika i svaki „paket“ je različit od korisnika do korisnika), a u trećoj fazi ga sprovodi. Četvrta faza predstavlja praćenje (monitoring, provera funkcionisanja) paketa i peta faza je evaluacija odnosno ocenjivanje ishoda pripremljenog paketa za konkretnog korisnika (mogućnost redefinisanja u toku rada obezbeđuje funkcionisanje). Ono što je važno istaći jeste da su pružanje usluga vođene potrebama korisnika i da se zasnivaju na odabiru usluga koje odgovaraju posebnim potrebama svakog korisnika (Žegarac, 2016b).

Ciklus vođenja slučaja može se objasniti i detaljnijim fazama (Žegarac, 2007) koje su međusobno povezane:

- Prijem - prijem zahteva, uputa i prijava i informisanje o pravima, nadležnostima i pristupačnim oblicima podrške i pomoći. Najčešće rad započinje prijemom nakon zahteva korisnika ili porodice za uslugom ili pomoći, ili kada neka druga institucija, služba ili građanin upute korisnika u centar. Prijemni radnik pregleda raspoložive informacije i odlučuje o daljim aktivnostima. Slučaj se ili upućuje drugoj službi (slučaj se ni ne otvara) ili se otvara ukoliko je problematika slučaja za centar za socijalni rad. Prijemni radnik ocenjuje nivo prioriteta početka rada na slučaju (urgentan-24 sata, hitan-3 dana ili redovan-7 dana).

- Procena - stanja i potreba da bi smo videli koja vrsta pomoći i podrške je potrebna za prevazilaženje problema ili zadovoljavanje potreba. Procena podrazumeva organizovan proces prikupljanja podataka, prepoznavanja i ocene problema, potreba, snaga i rizika, situacije i uključenih osoba, koji se 
postepeno razvija kako bi se odredili ciljevi rada sa korisnikom, potrebne usluge i mere.

- Planiranje usluga - usluge se planiraju na osnovu utvrđene individualne potrebe korisnika, potencijala i ograničenja. Osnovni elementi plana usluga su ciljevi, oblasti problema, aktivnosti, vremensko trajanje, ishodi, mehanizmi praćenja, obezbeđivanje aktivnog učešća korisnika i članova porodice. Plan usluga formuliše se u pisanoj formi.

- Aranžiranje pristupa uslugama i upućivanje - podrazumeva da je korisnik povezan sa osobama, organizacijama, službama i ustanovama iz sistema socijalne zaštite ali i iz obrazovnog, zdravstvenog, sistema zapošljavanja, pravosuđa i policije. Multisektorska saradnja u rešavanju problema, podeljene i usaglašene uloge i odgovornosti su od velikog značaja. Ponekad voditelj slučaja u radu na konkretnom slučaju sa pojedincem ili porodicom, posle procene stanja i potreba, definiše (uz aktivnu participaciju korisnika i porodice) adekvatne usluge i uputi korisnika kako i gde da ih koristi. Nekada se ovaj zadatak završi jednostavno, ali kod složenih situacija i potreba nekih korisnika i njihovih porodica aranžiranje pristupa uslugama zahteva složene aktivnosti (pronalaženja resursa, višestruke i ponovljene kontakte, pregovaranja, zalaganja, zastupanja, ugovaranja i sl.) voditelja slučaja koje zahtevaju značajno vreme, multisektorski pristup i aktivan rad.

- Koordinacija usluga - vezana je za pojedinačnog korisnika i konkretni slučaj, a obuhvata koordinaciju usluga i saradnju sa službama kako bi se zajednički odgovorilo na potrebe korisnika.

- Monitoring - praćenje i nadgledanje kako su usluge obezbeđene, da li odgovaraju na potrebe korisnika, da li postoje problemi u sprovođenju plana. Na osnovu monitoringa se može revidirati plan usluga.

- Evaluacija - ponovni pregled u kome je cilj da korisnici prevaziđu stanje koje je zahtevalo korišćenje usluga pa mu dalje usluge nisu potrebne i „dalje u život može sam“. Evaluacijom utvrđujemo da li su usluge koje su do sada pružene korisniku delotvorne kao i da li su potrebne još neke dodatne usluge.

- Završetak rada - kada korisnici realizuju plan usluga, „izađu iz sistema“ potrebno je obrazložiti proces rada, preduzete usluge, intervencije, mere i evidentirati potrebne podatke. 


\section{ZADACI I ULOGE VODITELJA SLUČAJA}

Osnovni zadaci voditelja slučaja, kako navodi Žegarac (2007), jesu da on vodi proces procene, a da pri tom prikuplja podatke od korisnika, njegove porodice, sistema i službi koji su uključeni i formira mišljenje o potrebama za određeni slučaj. Dalje, voditelj slučaja razvija plan usluga, određuje cilj, kao i specifične zadatke koji će se koristiti za praćenje slučaja. Pružanje podrške i uspostavljanje i održavanje veze sa korisnikom, njegovom porodicom i odgovarajućim službama jeste specifičan zadatak koji voditelj slučaja ima. Nakon toga, profesionalac koji je zadužen za slučaj ima zadatak da prati i dokumentuje procenu napretka sa značajnim informacijama i promenama nastalim tokom samog rada. Ukoliko je potrebno, daje svoje mišljenje sudu. Na osnovu ciljeva i procene rada voditelj slučaja ima zadatak da razvija formalnu i neformalnu podršku, a ukoliko je potrebno, i da upućuje korisnika na druge službe. Voditelj slučaja ima zadatak da obezbedi informacije odgovarajućim službama, a čuvanje poverljivosti podataka o porodici, potrebama i problemima korisnika je zadatak koji je posebno važan za sve vaspitno-obrazovne institucije jer je razmena informacija od presudnog značaja za dobrobit učenika koji je obuhvaćen tretmanom ili uslugom organa starateljstva (Mihajlović Babić, Despotović, \& Đaković, 2019; Urbanc \& Ajduković, 2010). Zadatak voditelja slučaja je i da komunicira sa svima koji učestvuju u pružanju usluga, kao i da zastupa korisnika usluga.

Uloge voditelja slučaja tokom rada na slučaju zavise prvenstveno od službe u kojoj radi i od njegovih znanja, veština i iskustva u radu. Uloga koju voditelj slučaja ima u određenoj fazi rada omogućava pre svega ostvarivanje njegove profesionalne odgovornosti. Osnovne uloge (Woodside \& McClam, 2003) koje voditelj slučaja može da ima su zastupnik, posrednik, koordinator, saradnik, organizator zajednice, konsultant, savetnik, evaluator, izvršilac, planer, rešavalac problema, izvestilac i modifikator sistema. Kao zastupnik, voditelj slučaja pruža podršku korisniku da zastupa lične i porodične interese. Ukoliko korisnik nije u stanju da nastupa samostalno ili postoji neka vrsta diskriminacije, voditelj slučaja preuzima ulogu zastupnika. Kao posrednik, voditelj slučaja povezuje korisnika sa odgovarajućim službama i bavi se otklanjanjem teškoća sa kojima se korisnik potencijalno sreće. Kada je u rad sa korisnikom uključeno više sistema (obrazovni, pravosudni, socijalni, zdravstveni), voditelj slučaja preuzima ulogu koordinatora. On tada ima zadatak da korisniku obezbedi integrisano pružanje usluga. Saradnja kao uloga voditelja slučaja odnosi se pre svega na saradnički odnos sa drugim profesionalcima koji su uključeni u konkretni slučaj. Uloga voditelja slučaja kao organizatora zajednice pretpostavlja da će profesionalac koji je voditelj slučaja biti 
deo timova, radnih grupa i koordinacionih tela koji su usmereni na razvoj resursa sa ciljem unapređenja različiti organizacija i službi u zajednici. Voditelj slučaja u određenim situacijama postaje i konsultant. U toj ulozi njegov zadatak jeste da se konsultuje sa ekspertima iz specifičnih oblasti ukoliko je to neophodno da bi se pomoglo korisniku. Jedna od najčešćih uloga voditelja slučaja je uloga savetnika. On pruža usluge savetovanja kako korisniku, tako i njegovoj porodici. Evaluator postaje kada je potrebno proceniti stanje i potrebe za pružanjem usluge, kao i prilikom procene procesa pružanja usluge. Voditelj slučaja postaje izvršilac u situacijama gde postoje problemi sa kvalitetom pruženih usluga. Jedna od uloga je i razvoj plana, kao i njegovo definisanje i odvija se u saradnji sa drugim službama koje su uključene u slučaj, ali i sa korisnikom i njegovom porodicom. Voditelj slučaja ima često ulogu i rešavaoca problema, koji najčešće nastaju usled neusaglašenosti, nejasnoća i nedovoljne koordinacije usluga. Kao izvestilac, voditelj slučaja prikuplja informacije koje treba da dokumentuje. Nekada, profesionalac koji vodi slučaj postaje modifikator sistema. Voditelj slučaja najčešće radi u okviru jedne ili dve uloge u okviru jednog slučaja, u zavisnosti od brojnih faktora, koji pre svega uključuju njegove kompetencije, ali i potrebu određenog slučaja.

\section{Uloga voditelja slučaja u proceni i timskom radu}

Najčešće se procena u centru za socijalni rad sačinjava nakon nekog zahteva suda ili drugog organa, nakon prijave za novčanu nadoknadu ili uslugu, ili u situacijama kada je prijavljen slučaj zlostavljanja ili zanemarivanja. Procena predstavlja upoznavanje, prikupljanje, sistematizaciju i evaluaciju svih informacija do kojih je voditelj slučaja došao u toku rada sa korisnikom i njegovom porodicom. Početna procena planira se na osnovu raspoloživih podataka i saznanja o slučaju. Da bi došao do svih relevantnih informacija voditelj slučaja, uz konsultaciju sa supervizorom ili rukovodiocem službe, voditelj slučaja planira sa kim će kontaktirati, ko će sve biti intervjuisan (korisnik i osobe iz njegovog okruženja), ko će sve biti uključen u postupak (policija, zdravstvena služba, škola i dr.), posmatra ponašanje korisnika, pregleda dokumentaciju i koristi različite testove, skale i upitnike za procenu i stvaranje profesionalnog mišljenja i tačnih zaključaka korisnikovog funkcionisanja.

Usmerena procena se organizuje ukoliko je posle početne procene potrebno prikupiti još podataka i bliže i detaljnije proceniti pojedine oblasti procene. Ona prati rezultate početne procene, ali ne zaustavlja donošenje početnog plana i preduzimanje prvih planski zasnovanih usluga i intervencija. Ona traje najviše 30 
dana od dana okončanja početne procene (Žegarac, 2016b). U brojnim okolnostima treba sačekati rezultate specijalističke procene koja se odvija van centra za socijalni rad. Voditelj slučaja planira zajedno sa supervizorom na koje oblasti procene se treba dalje usmeriti, zatim planira kod kojih slučajeva je potrebno uključiti druge profesionalce centra za socijalni rad, kao i gde je potrebna saradnja stručnjaka iz drugih službi i ustanova. Voditelj slučaja, takođe, priprema i početni plan u roku od 15 dana od početka rada sa klijentom. U ovom planu se ukazuje na urgentne potrebe. On može da se izrađuje paralelno sa daljom usmerenom procenom. U roku od 60 dana od početka rada sa detetom i porodicom voditelj slučaja priprema porodični plan usluga i mera za porodicu i dete. Ukoliko je potrebno, plan sadrži starateljske i druge pravne mere zaštite, kao i ciljeve stalnosti za dete. Voditelj slučaja organizuje i sprovodi evaluaciju i ponovni pregled prema planu, u roku od 6 meseci (Žegarac, 2015).

Neposredni rad sa decom je važan deo procene, kao i prepoznavanje njihovih prava na uključivanje i konsultacije o stvarima koje utiču na njihov život. Ovo se odnosi na svu decu, uključujući decu sa smetnjama u razvoju (Dalzell \& Chamberlain, 2006). Stoga je važno uključivanje dece u procenu, planiranje i sve druge aspekte rada u centru, a koji se tiču njihovog života i odlučivanja o njihovoj budućnosti. Takva komunikacija treba da bude direktna, da voditelj slučaja posmatra dete, podstiče ga na razgovor, da traži njegovo gledište i da sluša njegova iskustva. Ista situacija je i sa korisnikom koji nije dete. Etika aktivnog učestvovanja i participacije u rešavanju sopstvenog problema daje nam konceptualni i vrednosni mandat da odustanemo od tzv. objektivnosti stručnjaka i zamenimo je razgovorom u kojem ničija reč „nije zadnja“, već se razgovor nastavlja na način slušanja u „suprisustvu“ (Čačinovič Vogrinčič, Kobal, Mešl, \& Možina, 2007; Tartakovsky, 2015), što je mnogo više od samog slušanja. Takav razgovor otvara prostor za novo razumevanje značenjem i opisima kojima onda otvaramo nove načine na koje definišemo probleme, izazove i rešenja.

Možemo da zaključimo da potrebe i problemi korisnika ponekad zahtevaju koordinisan multisektorski timski pristup. Rad po metodu vođenja slučaja doveo je do uspostavljanja novog načina timskog rada. Umesto stabilnih timova potrebni su tzv. međufunkcijski timovi odnosno timovi s unakrsnim funkcijama (Certo \& Certo, 2008; Robbins \& Judge, 2009). To konkretno znači da tim čine stručnjaci iste hijerarhijske strukture, ali različitih područija rada, koji se od situacije do situacije nalaze $\mathrm{u}$ različitom sastavu i različitim ulogama da bi zajednički rešavali neki konkretni problem, teškoću ili potrebu. Za razliku od dosadašnjeg timskog rada, timovi koji treba da osiguraju delotvoran rad na slučaju, u ovakvom sistemu rada 
puno su fleksibilniji. Uz stručne radnike centra za socijalni rad, pretpostavljaju i uključivanje stručnjaka koji dolaze izvan centra, što zahteva dodatne veštine, ali i jačanje uspostavljanja saradničkih odnosa centra za socijalni rad sa lokalnom zajednicom (Urbanc i Ajduković, 2010). U timu grupa ljudi koja ga sačinjava nadopunjuje se svojim znanjima i veštinama, posvećeni su zajedničkoj svrsi i ciljevima, odnosi se zasnivaju na poverenju i otvorenosti (Žegarac, 2015). Ovako organizovani timovi su korisni kako centrima za socijalni rad, tako i obrazovnim ustanovama, a najviše korisnicima.

\section{IMPLIKACIJE ZA OBRAZOVNI SISTEM}

Kao što se iz priloženog pregleda načina rada u centrima za socijalni rad može videti svi stručni radnici (socijalni radnici, pedagozi, psiholozi, specijalni pedagozi, defektolozi, andragozi) rade kao voditelji slučaja. Prema izveštaju o radu 170 centara za socijalni rad (Izveštaj o radu centara za socijalni rad u Srbiji, 2017), od ukupno 1.789 stručnih radnika prema vrsti poslova koje obavljaju bilo je angažovano 1.073 voditelja slučaja. Što se ostalih stručnih radnika tiče, 77 obavlja poslove supervizora, 140 obavlja istovremeno poslove i supervizora i voditelja slučaja, a 480 obavlja druge stručne poslove (od toga 302 čine pravnici). U centrima za socijalni rad u Srbiji od ukupno zaposlenih stručnih radnika $42 \%$ čine socijalni radnici, psiholozi $18 \%$, a pedagozi svega $10 \%$. Specijalnih pedagoga, andragoga i sociologa zaposleno je nešto više od $9 \%$, dok je pravnika zaposleno $18,4 \%$. Ukupan broj angažovanih radnika u centru za socijalni rad je smanjen za 18\%, dok je broj korisnika na evidenciji centra porastao za 4\% (Izveštaj o radu centara za socijalni rad u Srbiji, 2017). Postavlja se pitanje da li se u ovakvom multisektorskom okruženju jasne granice rada pedagoga gube ovakvim načinom rada kada su svi voditelji slučaja, ili svaka profesija, pa i pedagozi mogu da iskažu neku svoju specifičnost? Evidentno da je i pedagogu, andragogu i drugim profesijama potrebna pomoć radi ostvarivanja svih složenih i zahtevnih poslova voditelja slučaja. Od velikog je značaja zajednički, timski, saradnički rad voditelja slučaja kroz usmerene procene ali i superviziju. Iz pedagoškog ugla je značajno kako će se sticati znanja, koje metode i tehnike će doprineti napretku prakse socijalnog rada (Beljanski, 2011). Svaka profesija unosi nešto od svog specifičnog načina rada i načina sagledavanja slučaja i doprinosi uspešnoj proceni, praćenju i rešavanju socijalnih problema pojedinaca i porodica. Odgovarajuća primena vođenja slučaja uvezuje različite sisteme i bavi se stvarnim potrebama ljudi kroz različite profesije, različita znanja i pristupe. 
Poznavanje svih faza ovakvog načina rada može da predstavlja novi ugled centara za socijalni rad (Urbanc i Ajduković 2010) i utiče na promenu percepcije javnosti u odnosu na centar za socijalni rad i socijalnu zaštitu uopšteno, da centar ne bi bio prozvan i prepoznat jedino u negativnom kontekstu, kada se desi neki propust i neka tragedija. I sami zaposleni u centrima za socijalni rad naglašavaju njegovu lošu reputaciju, da su gledišta javnosti pretežno negativna i da se zasnivaju na nedovoljnim ili netačnim informacijama i pretpostavkama (Žegarac, 2016b). Stoga se čini da odnos prema socijalnim službama odražava opšti odnos društva prema marginalizovanim grupama, te da zanemarivanje potreba, stigmatizacija, diskriminacija i isključivanje sa kojim se susreće veliki broj korisnika socijalnih službi utiče i na službe koje se njima bave. Analizirajući opšte zadovoljstvo uslovima rada u centru za socijalni rad (Mihajlović Babić et al., 2019), više od polovine ispitanih zaposlenih ističe da je vrlo nezadovoljno svojim poslom najviše zbog visine mesečne zarade, nemogućnosti stručnog usavršavanja i nezadovoljno je radnim prostorom i opremom. Isto istraživanje je ispitivalo i domen profesionalne saradnje, naročito sa predstavnicima podsistema u društvu sa kojima centar neposredno sarađuje koja je ocenjena vrlo loše. Kao jedan od preduslova podizanja kvaliteta rada u obrazovnim ustanovama i ustanovama socijalnog rada je poboljšanje međuljudskih odnosa (Beljanski, 2016), što ukazuje na potrebu rada na podizanju kvaliteta saradnje, gde je svakako prvi korak poznavanje delokruga rada svakog sistema.

\section{ZAKLJUČCI}

Vođenje slučaja je prepoznato kao metod koji ima potencijal da dopre do ugroženih i isključenih pojedinaca i grupa tako što uzima u obzir njihove potrebe $i$ snage. Vođenje slučaja je prepoznato i kao praksa koja doprinosi integrisanom nastupu službi u zajednici. U značajnoj meri su u školama prisutni socijalni problemi, problemi u ponašanju, sve češće korišćenje psihoaktivnih supstanci, negativan uticaj interneta, izostanci sa nastave, neadekvatno korišćenje slobodnog vremena, vršnjačko nasilje (Žegarac, 2016b). Zaposleni u školama najmanje se bave socijalnim problemima (jer za to nemaju vremena ili nisu za to obučeni ili zaduženi). Pretpostavljamo da i među zaposlenima u školi postoji pozitivan stav prema uvođenju profesionalnog socijalnog rada u škole (i zakon kaže da postoji mogućnost) jer bi doprineo ostvarivanju vaspitne i socio-preventivne funkcije škole. Međutim, do sada nije bilo niti se planira pokretanje inicijative za uvođenje socijalnog rada u škole. Ono što se do tada može uraditi jeste rad na povezivanju i usklađivanju aktivnosti svih činilaca koji neposredno i posredno utiču na opšte 
funkcionisanje učenika u školi i na njihov uspeh, kroz interresornu saradnju prosvete, zdravstva i socijalne zaštite. Ta saradnja može biti obogaćena pravovremenim znanjima u vezi sa načinom rada svake od ovih aktera saradnje, što utiče na kvalitet saradnje i jasno razgraničavanje uloga, ali i očekivanja. Možemo da zaključimo da su saradnički odnosi među institucijama, ali i njihovim profesionalcima ključni za unapređenje vođenja svakog pojedinačnog slučaja, a interdisciplinarni pristup ovoj temi neizostavan faktor uspeha.

\section{Mila Beljanski, Borka Malčić}

\section{CHALLENGES OF CASE MANAGERS IN CENTERS FOR SOCIAL WORK: IMPLICATIONS FOR THE EDUCATION SYSTEM}

\section{Summary}

Starting from the fact that teachers in schools are often unfamiliar with the work of centers for social work, the paper analyzes issues through which the phenomenon of case management in the centers for social work is implemented. In Serbia, case management as a method of work in the centers for social work was legally introduced in 2008 in order to provide: a holistic approach for assessing the needs, strengths, and risks faced by the child and his/her family, an individual approach for planning services and interventions, introduction of the principle of planning permanence in social protection, as well as participation of children and parents as beneficiaries.

The paper describes in more details phases of the case management cycle: assessment of beneficiary's needs, planning and formation of the service to be provided, followed by the phase of service implementation, then monitoring, and finally evaluation of the outcome of the service provided. What is analyzed in the paper are the tasks and role of the case manager for the purpose of better cooperation among social services and educational institutions. Depending on the competencies of the case manager, the beneficiary's needs and other factors, a professional who is in the position of a case manager can have a role of a representative, a mediator, an associate, a coordinator, a community organizer, a consultant, an evaluator, an advisor, a supervisor, an executor, a problem solver, a system planner, and a system modifier. The case manager performs integrated tasks through these roles.

A special part of the paper is dedicated to the role and place of a case manager in the assessment of the situation, his/her place in the team work with other professional associates and services, as well as challenges he/she faces when beneficiaries are included in the assessment. After a detailed analysis of the case management and challenges faced by acase manager, implications on the education system are primarily related to connecting and coordinating activities of all stakeholders who directly or indirectly affect the student in the 
school, in this case the beneficiary of the center for social work. The purpose of this paper is to know and integrate the theory and practice of case management with educational institutions, to determine which services are connected, and which are in a direct relation and cooperation with the work of centers and social services.

The conclusion is that the education system must be familiar with the way of work, scopes, and possibilities of expert employees in the guardianship bodies, in order to have a successful cooperation. The help of experts, in this case the case manager, as well as the interaction of these two systems, can be complete only in the described way. It is confirmed that there is a need to establish and nurture a dialogue and cooperative relationships, which affect the quality of cooperation, as well as a clear delineation of roles and expectations by both professionals involved in the case and beneficiaries.

Key words: case management, center for social work, education system, case manager.

\section{LITERATURA}

Ajduković, M. (2008). Socijalni problemi, socijalni rizici i suvremeni socijalni rad. Revija socijalne politike, 15(3), 395-414.

Ajduković, M., \& Urbanc, K. (2009). Integrirajući pristup u socijalnom radu kao kontekst razumevanja individualnog plana skrbi. Ljetopis socijalnog rada, 16(3), 505-535.

Beljanski, M. (2011). Pedagoški izazovi u praksi supervizije socijalnog rada. Pedagoška stvarnost, 3-4, 235-240.

Beljanski, M. (2016). Supervizija ili o ličnom i profesionalnom usavršavanju odraslih. Andragoške studije, 1/2016, 129-142.

Certo, S. C., \& Certo, S. T. (2008). Moderni menadžment. Zagreb: MATE d.o.o.

Čačinovič Vogrinčič, G., Kobal, L., Mešl, N., \& Možina, M. (2007). Uspostavljanje suradnog odnosa i osobnog kontakta u socijalnom radu. Zagreb: Biblioteka socijalnog rada.

Dalzell, R., \& Chamberlain C. (2006). Communicating with children: A two-way process. London: National Children's Bureau.

Izveštaj o radu centara za socijalni rad u Srbiji (2017). Beograd: Republički zavod za socijalnu zaštitu.

Mihajlović Babić, S. (2017), Antipotčinjavajuća praksa u ostvarivanju prava na novčanu socijalnu pomoć - prepreke i mogućnosti. Godišnjak Fakulteta političkih nauka, 17, 151-170.

Mihajlović Babić, S., Despotović, M., \& Đaković, M. (2019). Izazovi za profesiju socijalnog rada nakon ekonomske krize u Republici Srbiji. DHS - 
Društvene i humanističke studije Časopis Filozofskog fakulteta u Tuzli, 1(7), 349-366.

NASW Standards for Social Work Case Management. (2013). https://www.socialworkers.org/LinkClick.aspx?fileticket=acrzqmEfhlo\%3 D\&portalid $=0$

Robbins, S. P., \& Judge, T. A. (2009). Organizacijsko ponašanje. Zagreb: MATE d.o.o.

Strier, R., \& Binyamin, S. (2010). Developing Anti-Oppressive Services for the poor: A Theoretical and Oganisational Rationale. British Journal of Social Work, 40(6), 1908-1926. https://doi.org/10.1093/bjsw/bcp122

Tartakovsky, E. (2015). Personal value preferences and burnout of social workers. Journal of Social Work, 16(6), 657-673.

Urbanc, K., \& Ajduković, M. (2010). Novi modeli rada centara za socijalnu skrb: izazovi i preporuke. Ljetopis socijalnog rada, 7(3), 353-389.

Žegarac, N. (2004). Deca koja čekaju. Izazovi i trendovi profesionalne prakse u zaštiti dece od zlostavljanja. Beograd: Save the Children UK, Centar za prava deteta.

Žegarac, N. (2007). Vodič za planiranje i procenu (materijal sa obuke).

Žegarac, N. (2015). Od problema do prilika u vođenju slučaja-priručnik za praktičare. Beograd: Fakultet političkih nauka i Centar za istraživanja u socijalnoj politici i socijalnom radu.

Žegarac, N. (2016a). Kompetencije za kvalifikacije u socijalnom radu: izgradnja standarda. U: Žegarac, N. (ured.). (2016). Standardi za obrazovanje socijalnih radnika u Srbiji (str. 9-45). Beograd: Fakultet političkih nauka..

Žegarac, N. (2016b). Mapiranje praksi i radne snage u oblasti zaštite dece u Srbiji. Beograd: Centar za integraciju mladih.

Walter, L. (2001). Socijalni rad u Evropi - prikaz jedne raznovrsne profesionalne grupe. U: S. Hessle, L. Walter, M. Payne, \& D. Zaviršek (ured.). (2001). Uspostavljanje međunarodnh standarda u visokom obrazovanju za socijalni rad (str. 17-34). Banja Luka: Filozofski fakultet Univerziteta u Banjoj Luci.

Whitaker, T., Weismiller, T., \& Clark, E. (2006). Assuring the sufficiency of a frontline workforce: A national study of licensed social workers-Executive summary. NASW.

Woodside, M., \& McClam, T. (2003). Generallist Case Management: A Method of human Servise Delivery. Pacific Grove, CA: Thomson - Brooks/Colle. 